\title{
PLATFORM ECOSYSTEMS: UNLOCKING THE SUBCONTRACTORS' BUSINESS MODEL OPPORTUNITIES
}

\author{
Enni Laine ${ }^{1}$, Otto Alhava ${ }^{2}$, Antti Peltokorpi ${ }^{3}$, and Olli Seppänen ${ }^{4}$
}

\begin{abstract}
Platform ecosystems facilitated by the internet are changing the way market mechanisms work. The platform ecosystem business model, using data and network effects, creates new rules for how value is created and delivered. The viral growth characteristic to platform ecosystems has already caused disruption in several industries. The purpose of the research is to explore business opportunities facilitated by the platform ecosystem business model in the construction sector through an example case of a residential building construction. The key concepts and underpinning logics of the platform ecosystem business model are defined. Interactions between the five lean principles and the platform ecosystem concept are reviewed. Finally, an example case of implementation is represented with the help of the platform business model canvas.
\end{abstract}

Keywords: Lean, platform ecosystem, business model design, network effect, construction industry

\section{INTRODUCTION}

While several legacy businesses such as transportation, healthcare, energy, and heavy industry have faced fierce competition after the emergence of platforms and lost remarkable market shares to start-ups, the management research over platforms has proliferated (Parker et al 2016, Thomas et al 2014; Porch et al 2015). The way in which platforms change the competition by transforming industries is now identifiable (Parker et al 2016). So far, the construction sector has not been taken over by a platform-based operator, although there is room for competition since all companies use similar business models (Pekuri et al 2013). Moreover, despite nearly a quarter century existence of the International Group for Lean Construction promoting lean principles, the construction sector's productivity has not improved (Teicholz 2013).

This research maps and analyses platform ecosystem-based business opportunities utilised by Über, Airbnb, Google, and other similar companies from the management research perspective in the context of the construction sector and Lean. The view of a General Contractor is adopted because they have the role of traditional matchmakers called gatekeepers (Parker et al 2016) and are thus most exposed to platform-based competitors often entering the market from outside the traditional industry boundaries (Evans and Schmalensee 2016, Alstyne et al 2016).

Doctoral Candidate, Department of Civil Engineering, Aalto University, Finland, enni.laine@aalto.fi Chief Technology Officer, Fira Oy otto.alhava@fira.fi

Assistant Professor, Department of Civil Engineering, Aalto University, Finland, antti.peltokorpi@aalto.fi

Professor of Practice, Department of Civil Engineering, Aalto University, Finland, olli.seppanen@aalto.fi 
The emergence of platform business models is a result of their overwhelming capacity to remove friction and waste (Evans and Schmalensee 2016), scale without investments (Moazed and Johnson 2016), and increase customer value by utilising network effects (Parker et al 2016, Choudary 2015) and excess capacity (Chase 2015). The theoretical foundations and central concepts of the platform business logics are used to define key aspects of a platform-based business model. The interaction of the key aspects with the Lean principles is further analysed. A residential building project case is analysed to exemplify the use of a platform ecosystem approach as a lean business model to add value for customers and suppliers in the construction sector.

\section{PlATFORM BUSINESS MODEL}

\subsection{Key concepts}

Thomas et al. (2014) have defined four platform streams based on the leverage method and architectural openness of the platform structure. They are: 1) organisational platforms, 2) product family platforms, 3) market intermediary platforms, and 4) platform ecosystems. This research focuses on understanding the underlying logic of the platform ecosystem, which is combining the logics from both the product family and the market intermediary streams. The platform ecosystem is architecturally open, orchestrating external resources as providers, producers, and customers. It uses all three different types of leverage methods to allow greater outputs from the available inputs. This is done by recombining shared assets, designs and standards (production leverage), facilitating the creation of new goods and services (innovation leverage), and by manipulating market pricing mechanism and access to reduce friction such as transaction and search costs (transaction leverage). (Thomas et al 2014)

Chase (2015) states that the platforms mobilise value which is hidden to excess capacity by engaging community and their assets, time, expertise, and creativity to collaborate through a participative infrastructure. The control of the overall product or service system is relinquished to a community of users in the roles of producers and consumers. The scaling of the community happens through a positive network effect which is a cycle where an increase of well managed value-creating actions increase the value of the platform which in turn attracts more users, increasing again the value-creating actions (Parker et al 2016, Choudary 2015). As the business logic is based on interaction and open access, coordination is needed for both maximising the value and the ease of use equally for providers and consumers. Control is mandatory for separating the best users from the rest and expelling the poorly behaving ones from the platform (Choudary 2015). Bi-directional rating and reputation mechanisms as well as personalisation of the service are examples of curation for users (Choudary 2015). A governance system is needed for orchestrating the platform in terms of participation management, value division, and resolving conflicts between producers and consumers (Parker et al 2016).

To gain positive network effects and viral growth, it is important to 1) reach critical mass to facilitate value creation (Evans and Schmalensee 2016), 2) take care of real-time customisation, curation and governance to manage the community (Choudary 2015), and 3 ) ensure that the selected value proposition of the platform is relevant and of high value for the users (Alstyne et al 2016). Choudary (2015) claims that two key components of the platform often neglected by traditional pipe-based businesses, which try to implement a platform concept, are 1) agile response to changing usage patterns and 2) continuous management of the platform health. These and the other underlying key mechanisms of 
the platform ecosystem are based on the underlying data acquisition and management structure. Traditionally the currency exchanged in the economic interactions is understood as money, but when platforms are considered, the data or social currency such as reputation may be equally or even more valuable than the actual monetary transactions provided by the value-creation activities in the platform (Choudary 2015).

\subsection{Platforms from construction sector's perspective}

Legacy business model designs in the construction sector are often based on the pipe model, which is the dominant business design in the industrial economy (Choudary 2015). In the pipe model the flow of value is linear and it is first produced upstream and then consumed in the downstream.

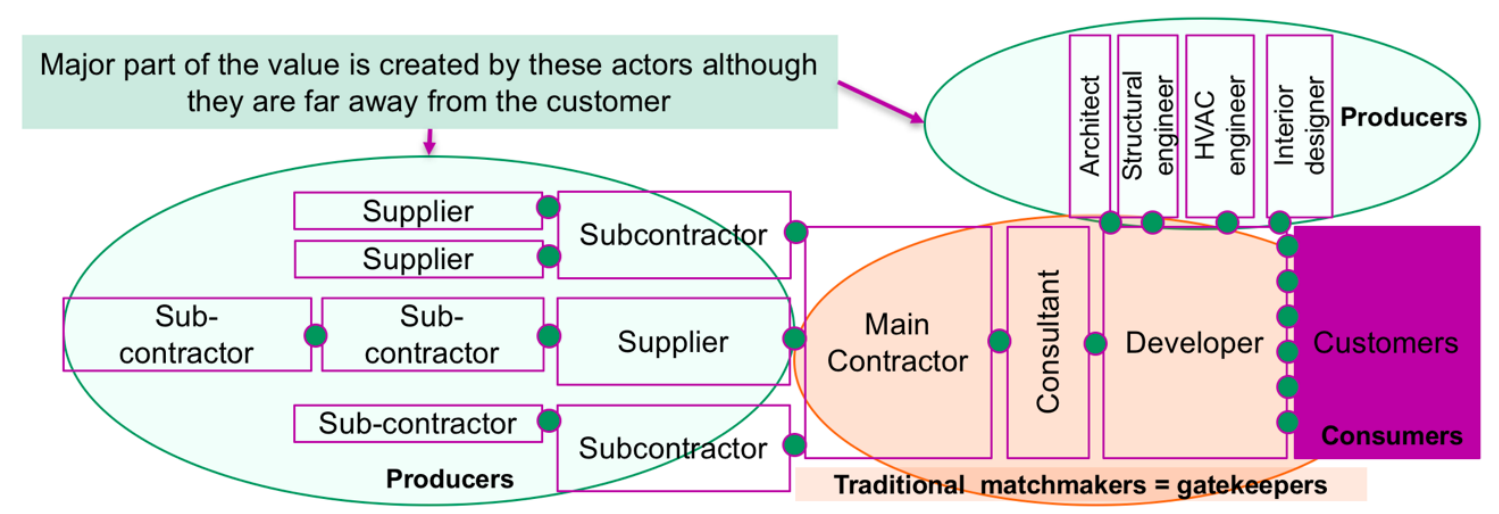

Figure 1: Traditional pipeline model with gatekeepers in the context of construction sector

Figure 1 presents the standard relations (green dots) of the actors in the construction process where the producers such as subcontractors, architects, engineers, and suppliers are rarely in direct collaboration with the consumers. Instead, the process and flow of value from producers to consumers is managed by inefficient gatekeepers (Parker et al 2016); namely developers and main contractors. These actors usually compete with resource ownership and control (Choudary 2015).

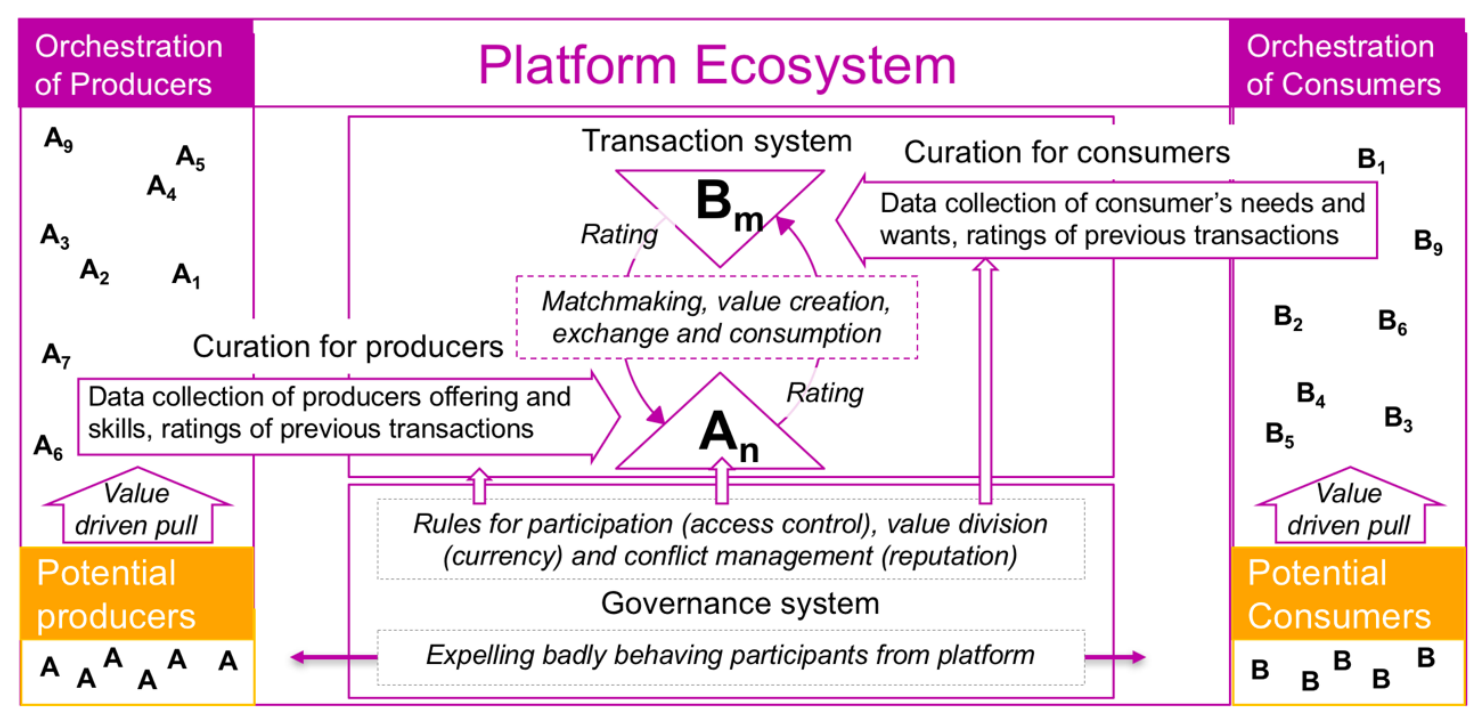

Figure 2: two-sided platform example and key parts of platform process 
Evans and Schmalensee (2016) argue that many of the formulas of the economics of the traditional business models are not valid when considering platforms. Unlike the pipe model, the platform business model represented in Figure 2 orchestrates value-exchanging interactions between various ecosystem partners (A's and B's) simultaneously, while the platform infrastructure utilising data collected through platform is replacing the gatekeepers (Choudary 2015).

Value creation is maximised by matching the most relevant resources from producers (A's) in the ecosystem with the need of those resources (B's). An easy plug-and-play connectivity reduces transaction cost by replacing existing expensive lock-in procedures such as the standard tendering process, which according to Hughes et al (2005) accounts for up to $9 \%$ of the subcontractors' annual turnover.

Moazed and Johnson (2016) summarise the delta between the pipeline business model and the platform business model in terms of cost efficiency and scalability: in the pipeline business model, a new user adds a single relationship (sub-contractor in Figure 1) whereas in a platform a new user ("A" in Figure 2) adds on a potential relationship with all the other users (B1, B2, etc.). Therefore, the platform business model replaces the linear pipelines due to a higher cost efficiency and exponential growth potential.

\section{PlATFORMS AND LEAN}

To understand if and how the platform principles interact with Lean theory, the five principles of Lean introduced by Womack and Jones (1996) are used to review the key concepts of the platform business model. The principles are Value, The Value Stream, Flow, Pull, and Perfection.

Value of goods and/or a service can only be defined by the customer. The concept of value also embeds a principle to improve the performance and delivered quality while the fundamental costs of deliverables are steadily pushed down (Womack and Jones 1996). According to Moazed and Johnson (2016), platforms capture data from each transaction and record bi-directionally the transaction satisfaction of both producers and consumers. This information is further used in the algorithms of the platform to match the most valuable producers with the individual needs of consumers. Also, these platforms reduce costs by removing unnecessary gatekeepers, i.e. pipeline companies. The very essence of platform ecosystem orchestration is in line with value definition.

Value Stream stands for three critical steps: problem solving, information management, and a physical transformation task (Womack and Jones 1996). The Value Stream is an approach in the pipeline system whereas the platform, although aiming to solve customer problems in a desired way, does not work as the Value Stream but rather as a value network. The platforms only flourish if they succeed in matching the right producer for the consumer and delivering maximised value for them both (Parker et al 2016). Therefore, they are in line with the lean principle.

The third lean principle is Flow. Lean organisations focus on a steady flow from one activity to another without interruptions. The platform ecosystem replaces entire companies, i.e., gatekeepers, from the value chain when they introduce a new business model, which removes end-to-end friction from a market of pipeline companies (Parker et al 2016). Platform ecosystems extend the concept of flow from the individual company and the individual project to the ecosystem level.

The fourth principle, Pull, is embedded in the platform logic. A successful platform creates a network effect, which increases the value of the platform for each participant of the platform every time a new producer or a new consumer plugs-in to the platform and 
increases the double-sided pull. A platform owner balances the demand and supply by adjusting the pricing. (Evans and Schmalensee 2016)

The platform business model is a powerful tool for Perfection. Platform ecosystems compete not only with pipelines but other platforms. In the future, it will be more common for consumers or producers to be engaged in more than one similar platforms (Parker et al 2016). These multi-homing participants will foster Perfection. The real-time feedback cycle with the big data management enforces the community to act against waste, while the governance system prevents bad behaviour (Choudary 2015). The continuous strive towards Perfection is built-in to the curation processes and governance systems of platforms.

All five Lean principles are naturally embedded in the success factors of the platform ecosystem. Especially Flow, while it is a key factor for a successful construction project, needs to be further addressed as it has not been sufficiently addressed by the current gatekeepers. Overall, platforms highlight the importance of understanding and embracing of customer value, which according to Pekuri et al. (2013) has been long overlooked by the construction sector.

Moreover, while it has many useful aspects to support the Lean implementation, the platform ecosystem is a new concept for the Lean Construction community. When searching the IGLC conference paper database with the term "platform ecosystem", no results appear. However, the search "platform" returns 13 results. In two cases the platform is used in the context of the production family platform (Jensen et al 2013, Kalsaas 2013). In three other cases a software platform facilitating real time information sharing was discussed (Azambuja et al 2013, Dave et al 2010, Faloughi et al 2014) but these software platforms, although considered an essential part of a well-functioning platform ecosystem, do not alone comply with the platform ecosystem framework. The rest of the papers utilised the term "platform" in a different context than the one used in this research.

\section{CASE STUDY: RED VELVET ROSE WALLPAPER}

\subsection{Case description}

A restriction of the conventional value creation mechanism utilised in the legacy pipeline based construction process is demonstrated by a customer change example. A buyer of an apartment (customer) finds a developer's wallpaper selection unsatisfactory. The developer's assortment, although designed to provide alternatives to the customer, is limited due to standardisation. The rationale for the standardisation from the developer's perspective is to reduce additional transaction costs and variation in the process caused by the customers' change requests.

Instead of selecting from the standard assortment, the customer requests for red velvet rose wallpaper from a specific producer, which is not available through regular purchasing channels. A negotiation on how to proceed with a non-standard change request is conducted within the production pipeline. It is agreed that if the customer will purchase and deliver the material, a sub-contractor can install it.

Figure 3 presents the communication flow of the change request through the pipeline process. When the change request is analysed from the gatekeeper's perspective, it is often only considered waste or variation that should be minimised to ensure the flow in the process. However, when observed from the consumer's perspective, the completion of the request is of high value. 


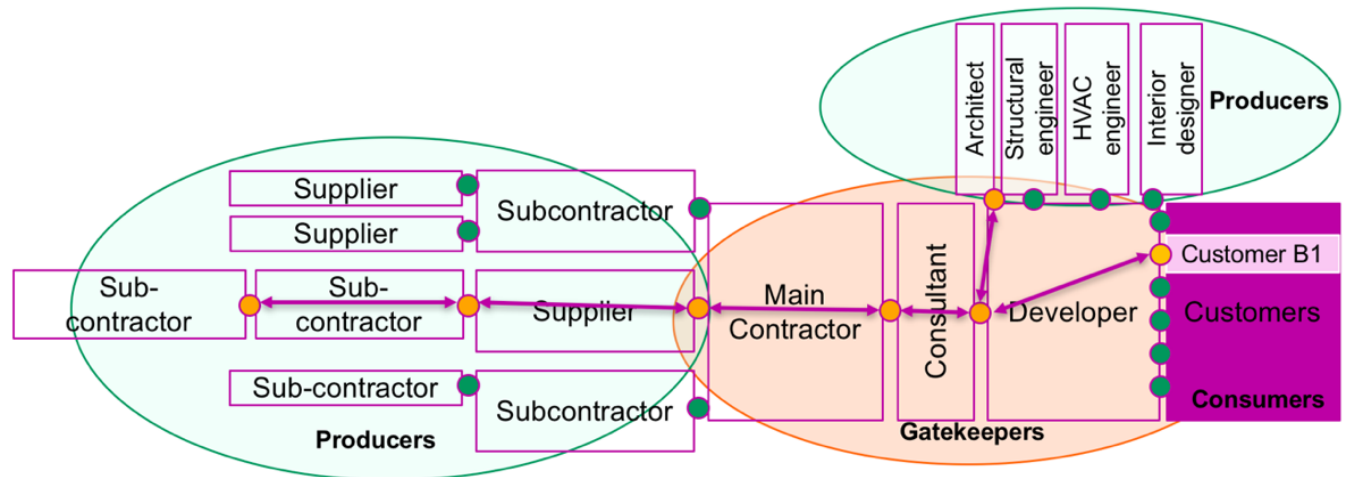

Figure 3: Case example: the purple arrows show the communication flow, whereas the small yellow circles represent the points of communication

Since the demand from the sub-contractor's current direct customers (main contractors) has lead them develop their business model to be excellent in working with standard assortment, the completion of a non-standardised customer request requiring different skills results in poor quality and needs to be rectified. The rework leads to value destruction of both the customer and the sub-contractor since the hand-over of the apartment is delayed and the rectification costs including purchase of the wallpaper are borne to the sub-contractor. Gatekeepers suffer the least since they are only coordinating the work.

\subsection{Platform business model implementation}

The platform ecosystem replacing the traditional pipeline based construction process provides a solution for removing the transaction cost, reducing the number of gatekeepers, and creating more value to the consumers and producers with less investment and contribution. The hypothetical implementation of the case example is depicted in Figure 4 by utilising the platform business model canvas introduced by Choudary (2015).

In the case example the platform's producer is the sub-contractor and respectively the consumer is the apartment buyer. When applied to the wider construction sector's perspective the producers can also include suppliers, architects and interior designers, whereas the consumers can be individuals or groups in need of construction services and/or building products or materials.

\begin{tabular}{|c|c|c|c|c|c|}
\hline \begin{tabular}{|l|}
\multicolumn{1}{c|}{ Producer } \\
Supplier, \\
Subcontractor, \\
interior \\
designer, \\
architect, \\
engineer etc.
\end{tabular} & $\begin{array}{l}\text { Channels + access control } \\
\text { Channel: } \\
\text { Webpage, applications, etc. } \\
\text { lean production system, } \\
\text { Access control: quality } \\
\text { workmanship, honesty and } \\
\text { responsibility, offering } \\
\text { compliant with interface } \\
\text { standards }\end{array}$ & \multicolumn{2}{|c|}{$\begin{array}{l}\text { Value } \\
\text { For consumers: unlimited assortment offering } \\
\text { for building parts, equipment and materials, } \\
\text { efficient execution of works and increased } \\
\text { innovative customised service offerings } \\
\text { For producers: direct access to the consumer } \\
\text { demands, possibility differentiate offering, flow } \\
\text { of work and information, reduced bidding cost } \\
\text { Core unit of value creation: Profile listing }\end{array}$} & $\begin{array}{l}\text { Channels + filters } \\
\text { Channel: Webpage, } \\
\text { applications, real } \\
\text { estate agent, etc. } \\
\text { Filters: Relevancy } \\
\text { based on budget, } \\
\text { previous interest, } \\
\text { size, etc.. }\end{array}$ & $\begin{array}{c}\text { Consumer } \\
\text { Apartment } \\
\text { buyer }\end{array}$ \\
\hline & Creation & Curation \& Customization & \multicolumn{3}{|c|}{ Consumption } \\
\hline \multicolumn{2}{|c|}{$\begin{array}{l}\text { Standardized interface to plug in service } \\
\text { offering or products }\end{array}$} & $\begin{array}{c}\text { Platform } \\
\text { Tools and Services (standardised production system with standardised interfaces, lean construction) }\end{array}$ & \multicolumn{3}{|c|}{$\begin{array}{l}\text { Visualisation of the offering alternatives in the } \\
\text { apartment, newsfeed, special offers etc. }\end{array}$} \\
\hline & $\begin{array}{l}\text { Currency } \\
\text { Money + reputation }\end{array}$ & Share of ev & job (prod & $\begin{array}{l}\text { apture } \\
\text { uction package) comp }\end{array}$ & \\
\hline
\end{tabular}

Figure 4: The case example depicted on the platform business model canvas

The key tools of the case platform are a Lean production system and standardised interfaces between production packages. The purpose of the Lean production system is to 
facilitate flow of the process. The production packages and interfaces divide the works into pieces small enough to manage which further enables providers to create diversified offerings. All basic platform principles including the real-time customisation, curation and governance as well as controlled standard access channels through webpages and mobile applications need to be in place. The access of the producers is controlled by construction professionals to ensure the quality and relevancy for the consumers whereas the services and products offered to the consumers are filtered based on their interests and prior behaviour on the platform.

The value of the platform for the producers includes 1) efficient resource allocation matching the consumer needs, 2) continuous flow of activities and standardised interfaces, 3) just-in-time delivery of consistent information facilitated by advanced data management, and 4) minimised tender costs with plug-and-play access to the platform. Moreover, the direct interaction between consumers and producers unlocks the unmet demand for customised offering enabling producers to diversify both their offering and business model design. The value proposition for the customer is thus composed of a personalised, high quality, low price apartment combined with a shorter throughput time of the work and diversified offering from the various producers. Additionally, the platform has potential to open new business opportunities to innovative producers that are unable to provide any services for the consumers in the existing market environment dominated by legacy pipeline process.

The main currencies that are exchanged as a result of value-creating actions are money and the reputation of the users. The capture, i.e. the return of investment, for the platform owner is composed of two main components: the data collected on the platform and money. The operator takes a cut of each transaction whenever money is exchanged through the platform. The underlying collection and orchestration of the data necessary for governance, curation, and filtering purposes facilitates the further potential advantages of the platform business model. The real time social feedback cycle works as a powerful distributed quality control quickly revealing mechanisms resulting in poor quality construction work. Moreover, the monetisation opportunities of the data gathered by the platform are unthinkable for the legacy construction process actors.

\section{RESEARCH LIMITATIONS}

This research is based on a literature study and an exemplary case. The target of the case is first to demonstrate a failure of the value creation mechanism utilised by the prevailing pipeline-based business model in the Finnish construction sector. Secondly, it hypothesises a few aspects of platform ecosystem's value creation potential in the construction sector. To test and implement a platform ecosystem based business model in the construction sector, further research is needed.

\section{CONCLUSIONS}

This paper demonstrates through an example that there is space for improvement in value creation in the construction process. The platform ecosystem has the potential to work as a tool to develop leaner practices in the sector. However, it was also noted that although the key platform principles are in line with Lean principles, the platform concept as such does not sufficiently address all of them. It is crucial to develop a platform architecture that enables and supports the flow of concurrent and sequential value-creating activities needed in construction projects. To conclude, acknowledging the limited scope of this 
research it is recommended that platform ecosystems are studied further within the construction community.

\section{REFERENCES}

Alstyne, M.W., Parker, G.G., and Choudary, S.P. (2016) Pipelines, Platforms, and the New Rules of Strategy. Harward Business Review, 94(4), pp.54-62

Azambuja, M., Schnitzer, T., Sahin, M., and Lee, F. (2013) Enabling Lean Supply with a Could Computing Platform - An Exploratory Case Study. In: Formoso, C.T. \& Tzortzopoulos, P., 21th Annual Conference of the International Group for Lean Construction. Fortaleza, Brazil, 31-2 Aug 2013, pp. 205-214

Chase, R. (2015) Peers Inc: How People and Platforms Are Inventing the Collaborative Economy and Reinventing Capitalism. Public Affairs, New York.

Choudary, S.P. (2015) Platform Scale: How a new breed of startups is building large empires with mimimum investment. Singapur. Platform thinking labs.

Dave, B. , Boddy, S. \& Koskela, L. (2010). Improving Information Flow Within the Production Management System With Web Services In:, Walsh, K. \& Alves, T., 18th Annual Conference of the International Group for Lean Construction. Haifa, Israel, 14-16 Jul 2010. pp 445-455

Evans, D.S, and Schmalensee, R. (2016/1). Matchmakers: The New Economics of Multisided Platforms. Harward Business Review Press.

Faloughi, M., Bechara, W., Chamoun, J., and Hamzeh, F. (2014) Simplean: An Effective Tool for Optimizing Construction Workflow. In:, Kalsaas, B.T., Koskela, L. \& Saurin, T.A., 22nd Annual Conference of the International Group for Lean Construction. Oslo, Norway, 25-27 Jun 2014. pp 281-292

Hughes, W., Greenwood, D., and Hillebrandt P. (2005). Impact of Procurement Method on Costs of Procurement in Globak Perspectives in Kähkönen, K. \& Porkka J. Management and Economics in the AEC Sector. VTT Technical Research Center of Finland, pp.214-226.

Jensen, P., Larsson, J., Simonsson, P., and Olofsson, T. (2013) Improving Buildability with Platforms and Configurators

Kalsaas, B.T. (2013) Improving Buildability with Platforms and Configurators

Moazed, A. and Johnson, N.L. (2016). Modern Monopolies: What It takes to Dominate the $21^{\text {st }}$ Century Exonomy. St. Martin's Press.

Parker, G., Van Alstyne, M.W., Choudary S.P. (2016). Platform Revolution: How networked markets are transforming the economy - and how to make them work for you. WW Norton \& Company.

Pekuri, A., Pekuri, L., and Haapasalo, H. (2013). The Role of Business Models in Finnish Construction Companies. Construction Economics and Building, 13(3), pp.13-23

Porch, C.,Timbrell, G., and Rosemann, M. (2015) Platforms: A Systematic Review of The Literature Using Algorithmic Historiography, IN ECIS 2015 Proceedings. Paper 143. Available at: http://aisel.aisnet.org/ecis2015_cr/143 , [Accessed 16th Jan. 2017]

Teicholz P. (2013) "Labor-Productivity Declines in the Construction Industry: Causes and Remedies (Another Look)” AECbytes Viewpoint \#67, March 14, 2013.

Thomas, L.D., Autio, E., and Gann, D.M. (2014). Architectural leverage: putting platforms in context. The Academy of Management Perspectives, 28(2), pp. 198-219, doi:10.5465/amp.2011.0105.

Womack, J.P., and Jones, D.T. (1996). Lean Thinking: Banish waste and create wealth in your corporation. Simons \& Schuster, Inc. 